\title{
DE HERENCIAS MANIPULADAS Y DE RECEPCIONES PERVERSAS: NIETZSCHE Y EL NACIONALSOCIALISMO
}

On Manipulated Heritage and Perverse Receptions: Nietzsche and National Socialism

\author{
Roberto Navarrete y Eduardo Zazo \\ Universidad Autónoma de Madrid
}

\begin{abstract}
REsUmen: Este trabajo ofrece una historia de la recepción del pensamiento de Friedrich Nietzsche a partir del hecho histórico de su perversa utilización por parte del nacionalsocialismo. Se analiza, en primer lugar, el proceso de politización, germanización y nazificación del pensamiento de Nietzsche, facilitado por la mutilación de su obra que realizó la hermana del filósofo. Se describen, en segundo lugar, las diversas estrategias de despolitización y desnazificación del pensamiento y la obra nietzscheanos, aplicadas desde la misma década de los años treinta del siglo pasado. Se ofrece, en tercer lugar, un breve resumen sobre la cuestión «Nietzsche y el nacionalsocialismo».

Palabras clave: Nietzsche - nacionalsocialismo - política - Alemania
\end{abstract}

ABSTRACT: This paper will offer a history of the reception of Friedrich Nietzsche's thought from the fact of his perverse use by National Socialism. Firstly, the process of politization, germanization and nazification of his thought will be analysed, showing how this was facilitated through the mutilation of Nietzsche's work done by his sister. Secondly, the various strategies implemented from the 30 s to depoliticize and denazificate his thought and work will be described. Last, a brief summary about the topic «Nietzsche and National Socialism» will be presented.

Keywords: Nietzsche - National Socialism - Politics - Germany

La historia de la recepción del pensamiento de Friedrich Nietzsche está inevitablemente asociada con el nacionalsocialismo. La cuestión de la relación entre ambos resulta ineludible todavía en nuestros días, en especial cuando de Nietzsche y la política se trata. La interpretación de su pensamiento, sobre todo de su pensamiento político, no puede obviar su empleo, uso y manipulación por parte del nacionalsocialismo. No es precisamente una cuestión menor que el autor de Así habló Zaratustra fuese responsabilizado intelectualmente de una guerra que pudo haber sido del fin del mundo ${ }^{1}$ y que de hecho lo fue de uno: el mundo

1. Sobre esta definición de la Segunda Guerra Mundial, véase M. García-Baró, «El hitlerisme com a filosofia i la degeneració del liberalisme», en La filosofia com a dissabte, trad. de I. Ferré, Barcelona: Cruilla, 2013, p. 75, así como E. Levinas, «Algunas reflexiones sobre la filosofía del hitlerismo", en Nietzsche y la "gran politica»: antídotos y venenos del pensamiento nietzscheano, ed. de A. Moraleja, Cuaderno Gris, época III, 5 (2001), 161-167. El ensayo de Levinas, quien ve en la glorificación de la voluntad de poder nietzscheana el ideal nacionalsocialista, data de 1934. 
judeo-alemán — cuyo último gran exponente, por cierto, reivindicó a Nietzsche, en 1921, como germen de su propio pensar ${ }^{2}-$. Es, por el contrario, un asunto de primer orden para la historia de las ideas, del pensamiento nietzscheano y de su relación con la historia política efectiva. Nietzsche fue objeto de interpretaciones sesgadas e interesadas pero (trágicamente) posibles, especialmente a partir de la mutilación y las graves falsificaciones a las que se vio sometida la obra nietzscheana. Nos referimos a la confección, por Elisabeth Förster-Nietzsche y Hermann Köselitz (llamado Peter Gast por su amigo Nietzsche), de La voluntad de poder (1901), elaborada a partir de los póstumos de la última década de lucidez del filósofo. La obra fue presentada como expresión verdadera y definitiva del pensamiento de Nietzsche. Más tarde, fue reivindicada como tal por los ideólogos del Tercer Reich. De entre ellos, quienes habían leído a Nietzsche, tuvieron algunas razones para hacerlo, aunque acaso tantas como para todo lo contrario ${ }^{3}$.

\section{POLITIZACIÓN, GERMANIZACIÓN Y NAZIFICACIÓN DE LA OBRA DE FRIEDRICH NIETZSCHE}

Erraríamos sin duda, y equivocaríamos con ello al lector, si omitiésemos el hecho de que hubo un Nietzsche antes de Nietzsche o, más exactamente formulado, antes del caso Nietzsche, por el que sin embargo ha pasado de un modo u otro el problema hermenéutico relativo al filósofo de Röcken desde 1945: hubo el hombre Nietzsche, que nada supo del fascismo ni del nacionalsocialismo, y hubo una recepción del pensamiento de Nietzsche en clave apolítica o antipolítica con anterioridad a su nazificación. El conflicto de las interpretaciones sobre las implicaciones políticas de la obra nietzscheana no surge en la ominosa y sombría época de los totalitarismos, sino incluso en vida del autor, convertido por su hermana en un verdadero ídolo, objeto de culto, tras su colapso mental ${ }^{4}$.

En el momento en que el nacionalsocialismo quiso reivindicar la figura de Nietzsche como pilar filosófico fundamental, pudo en realidad hacerlo gracias a que aquélla ya había dado lugar a todo un difuso movimiento nietzscheano que,

2. F. Rosenzweig, La estrella de la redención, trad. de M. García-Baró, Salamanca: Sígueme, 1997, pp. 49-50.

3. Puede decirse en este sentido que Nietzsche participa de la misma «ambigüedad intemporal» que puede atribuirse al gran antipolítico alemán del siglo xx: Thomas Mann, a quien vamos a referirnos de inmediato. Cf. W. Lepenies, La seducción de la cultura en la historia alemana, trad. de E. Hernández Sandoica, Madrid: Akal, 2008, p. 38. Aunque se trata, como bien recuerda Detwiler, de una ambigüedad que en el ámbito político solamente es compatible con ciertas ideologías, e incompatible con muchas otras. Cf. B. Detwiler, Nietzsche and the Politics of Aristocratic Radicalism, Chicago: University of Chicago Press, 1990, pp. 3-4. Detwiler señala las reiteradas críticas de Nietzsche al «comunismo, el socialismo, el anarquismo, la democracia, el liberalismo, el sufragio femenino, los derechos del hombre, la igualdad de derechos ante la ley, la teoría del contrato social, el utilitarismo, el darwinismo social, el militarismo, el nacionalismo alemán, el Estado platónico, el Estado hegeliano, la Revolución francesa y el Reich bajo Bismarck», mientras que recuerda «su admiración por instituciones como el Estado griego, el Imperium Romanum y el Imperio ruso" y sus alabanzas «a Julio César, Alcibíades, César Borgia y Napoleón».

4. Cf. F. Tönnies, Der Nietzsche-Kultus. Eine Kritik, Leipzig: Reisland, 1897. 
de hecho, había rebasado ampliamente las fronteras alemanas, primero del Reich fundado por Bismarck y, después, de la República de Weimar ${ }^{5}$. Nietzsche, o el nietzscheanismo, no fue, probablemente nunca, un acontecimiento puramente alemán. La germanización de Nietzsche parte de la Konservative Revolution, verdaderamente impensable sin la referencia nietzscheana, tan decisiva para la reacción revolucionaria alemana como la Primera Guerra Mundial ${ }^{6}$. Y en la que en muy buena medida, aunque no sin las discontinuidades también existentes entre Nietzsche y el propio Movimiento Revolucionario Conservador, cabe encontrar las raíces del Germanofaschismus ${ }^{7}$.

Muy acertadamente, Jean Pierre Faye, en su magnífica monografía Los lenguajes totalitarios (1972), situó a Nietzsche en el centro mismo de la Revolución Conservadora y otorgó a Thomas Mann el rango de referencia fundamental al respecto $^{8}$. Redactadas entre 1915 y 1918, las Betrachtungen eines Unpolitischen - en absoluto apolíticas sino más bien todo lo contrario, de una politicidad extrema en razón precisamente de su aclamada apoliticidad, igualmente radical, y tremendamente irónica - pertenecen en efecto a la misma fase ideológica en la que Mann, en otro lugar, afirma que Nietzsche no era otra cosa que «revolución conservadora» ${ }^{9}$. Al igual que poco después Hugo Ball ${ }^{10}$ y, en general, la teoría del Sonderweg alemán, el autor de La montaña mágica sitúa a Nietzsche en la misma estela, de raíz en último término luterana, que Hegel. Pero a diferencia de aquel anarquista católico, próximo sin embargo a insignes conservadores como Carl Schmitt, lo ensalza como maestro espiritual eternamente unido, por lo demás, a las figuras de Arthur Schopenhauer y —tal y como lo querrá ulteriormente el nacionalsocialismo- Richard Wagner. Tres décadas después de la

5. La recepción de Nietzsche tuvo lugar en un primer momento en círculos artísticos de la época, adquiriendo notable influencia también en el izquierdismo alemán de finales del siglo XIX. Desde allí, pronto traspasó las fronteras de Alemania en dirección a Italia, Francia, España, Rusia e, incluso, Estados Unidos. El individualismo nietzscheano fue en estos lugares fuente de inspiración para diversas formas de anarquismo (muy arraigadas, por cierto, aunque no sólo, en círculos de origen judío).

6. Cf. A. Mohler, Die Konservative Revolution in Deutschland 1918-1932. Grundriß ihrer Weltanschauungen, Stuttgart: Friedrich Vorwerk, 1950, pp. 39, 43 y 116 ss.

7. Cf. J. P. Faye, Los lenguajes totalitarios, trad. de M. Abad, Madrid: Taurus, 1974, pp. 76 ss., así como, sobre el entramado de continuidades y discontinuidades existente entre las respectivas épocas de Nietzsche y de Hitler, D. Losurdo, Nietzsche. Il rebelle aristocratico. Biografia intellettuale e bilancio critico, Torino: Bollati Boringhieri, ${ }^{2} 2004$, pp. 836 ss.

8. Cf. J. P. Faye, op. cit., pp. 72 ss.

9. Th. Mann, «Russische Anthologie», citado en J. P. Faye, op. cit., p. 74. Por lo demás, es posible que, al titular sus escritos de guerra, Mann tuviese en mente el tercer parágrafo del capítulo "Por qué soy yo tan sabio», de Ecce homo, en el que Nietzsche se define a sí mismo como «el último alemán antipolítico». Lo que no es posible es que Mann supiese, en plena Primera Guerra Mundial, que H. Hoffmann von Fallersben, autor de las Unpolitische Lieder, lo fue también del himno preferido de Hitler, cuyo célebre primer verso reza: Deutschland, Deutschland über alles. Cf. J. L. Villacañas, «Heinrich Mann o el literato como vocación», en H. Mann, Por una cultura democrática. Escritos sobre Rousseau, Voltaire, Goethe y Nietzsche, trad. de H. J. Pérez López, Valencia: Pre-Textos, 1996, p. 19, así como F. Duque, Los buenos europeos. Hacia una filosofía de la Europa contemporánea, Oviedo: Nobel, 2003, p. 91.

10. Véase su ensayo de 1924 sobre "Las consecuencias de la Reforma», en Dios tras dadá, trad. de F. González Viñas, Córdoba: Berenice, 2013, pp. 1-191. 
publicación de su libro de guerra, desde el exilio y a la luz de la experiencia del nacionalsocialismo, así como de la conciencia de la filiación tanto nietzscheana como conservadora-revolucionaria del NSDAP, hubo de salir en defensa de Nietzsche, exonerándolo de todo antisemitismo y convirtiéndolo, no en el padre espiritual del fascismo, sino en aquel que, por medio de su filosofía del poder, mejor supo anunciarlo ${ }^{11}$.

La tradición de Weimar, impulsada por la hermana del filósofo desde la creación del Nietzsche-Archiv en 1894, acabó por vencer sobre aquella otra, con sede en Basilea, que encabezó Franz Overbeck, a quien en 1886 advertía Erwin Rohde acerca de ciertos escandalosos pensamientos de su todavía amigo Nietzsche, aquellos que más tarde utilizó el nacionalsocialismo para legitimarse filosóficamente ${ }^{12}$. El propio Overbeck redactó una serie de apuntes destinados a desmitificar la falsa figura que se estaba creando en torno a su amigo más íntimo (con quien había compartido casa en sus años de juventud y a quien había recogido en Turín en los primeros días de enero de 1889 tras su colapso). Estos apuntes, publicados tras la muerte de Overbeck por su discípulo Carl Albrecht Bernouilli en 1906 con el título Erinnerungen an Friedrich Nietzsche ${ }^{13}$, conformaron un punto de referencia crucial frente a la interpretación oficialista de los Archivos Nietzsche. Frente a la divinización de Nietzsche, Overbeck trató en esos fragmentos de humanizar a su amigo, de mostrar un Nietzsche sin aura, un Nietzsche humano, con sus miserias y sus debilidades. El hecho es, sin embargo, que la nazificación de Nietzsche no se detuvo, favorecida por el papel desempeñado por Elisabeth Förster-Nietzsche, primero en relación con los conservadores revolucionarios y, ya en vísperas del colapso de la República de Weimar, con la jerarquía nacionalsocialista. Desde 1933, el Archiv fue financiado por el NSDAP. El propio Hitler lo visitó en varias ocasiones y fue incluso agasajado por la hermana del filósofo con uno de los bastones de éste. El Archiv fue asimismo sede de conferencias de ideólogos nacionalsocialistas de alto rango ${ }^{14}$. A la postre, tras

11. Cf. Th. Mann, «Nietzsches Philosophie im Lichte unserer Erfahrung (1948)», en F. Nietzsche, Also sprach Zarathustra, Frankfurt a. M.: Insel, 1994, pp. 354 ss. Para entonces, su hermano Heinrich había publicado ya un escrito en el que quiso también defender a Nietzsche del terrible culto póstumo que había alcanzado su obra, instando a «volver a leerlo verazmente, con los ojos de un joven de veinte años, nuevos sus pensamientos, inmaculada su gloria» (H. Mann, «Nietzsche [1939]", en Por una cultura democrática. Escritos sobre Rousseau, Voltaire, Goethe y Nietzsche, cit., p. 61).

12. Seguían siendo escandalosos, por ejemplo, en 1893 o 1899. Cf. L. Stein, Nietzsches Weltanschaunng und ihre Gefahren, Berlin: Reimer, 1893, y E. Lichtenberg, La filosofía de Nietzsche, trad. de J. E. Matheu, Madrid: Daniel Jorro, 1910, p. 239. Sobre los temores de Rohde, cf. D. Losurdo, op. cit., p. 773. Merece la pena señalar aquí el hecho cuando menos sorprendente de que el autor de esta monumental obra proceda a exculpar a Elisabeth Förster-Nietzsche en relación a la recepción nacionalsocialista del pensamiento de su hermano (ibid., pp. 767 ss.). Losurdo tiene razón al recordar que La voluntad de poder vio la luz cuando el Tercer Reich era todavía algo impensable, pero omite toda referencia al hecho, igualmente histórico, de la muy estrecha relación que, a través del Archivo, mantuvo la hermana de Nietzsche con el NSDAP, desde 1930 hasta literalmente su entierro.

13. F. Overbeck, La vida arrebatada de Friedrich Nietzsche, trad. de I. de los Ríos, Madrid: Errata naturae, 2009.

14. Por ejemplo, de Hans Frank, al frente del gobierno de Polonia desde 1939, o de Alfred Rosenberg, responsable de política exterior del Reich desde 1933 y, desde 1941, ministro para los 
la caída del Reich, y puesto que Weimar formó parte de la extinta RDA, a esta nazificación del Archivo, consentida y auspiciada por su fundadora, le sucedió su cierre al público por las autoridades soviéticas, que convirtieron a Nietzsche en un autor prohibido. A esta condena política corresponde, u obedece más bien, la condena filosófica del pensamiento nietzscheano llevada a cabo por Georg Lukács, cuyo Nietzsche, por lo demás, no fue otro que precisamente el del nacionalsocialismo y, en particular, el filósofo político de Alfred Bäumler ${ }^{15}$.

Existe un consenso generalizado a la hora de evaluar a Bäumler como algo más que un mero ideólogo del nacionalsocialismo. Ello vale para su estudio de la tercera Crítica kantiana, publicado en 1923, pero también para su Nietzsche (1931), que en modo alguno es el de un Hitler o un Rosenberg, de quienes más bien cabe dudar, no ya de que entendieran algo de lo escrito por el filósofo de Röcken, sino de que siquiera lo hubiesen propiamente leído. Del estudio de Bäumler se ha dicho que «reconstruye con precisión y reflexión filosófica un nexo de pensamiento que se da de hecho en Nietzsche» ${ }^{16}$. En él encontramos la exaltación de los elementos heraclíteos del devenir y del polemos, al precio de suprimir la doctrina del eterno retorno, que en efecto no era adecuada a los intereses del Partido al que, en definitiva, obedecía este exégeta de Nietzsche. La lectura de Bäumler, no es ocioso recordarlo, parte de la mutilación de la obra de Nietzsche que significó, como ya tuvimos ocasión de mencionar, la aparición en escena, más a modo de interpretación oficial que como mero hecho neutral, de La voluntad de poder: la falsificación, en la interpretación de Bäumler, está en la unilateralidad.

Con independencia de si la apropiación nacionalsocialista del pensamiento nietzscheano produjo o no una distorsión en éste, si fue verdadera o falsa a nivel exegético, es simplemente un hecho histórico que Nietzsche fue incorporado al panteón nacionalsocialista de héroes de la germanidad, convirtiéndose en parte integral de la imagen que el propio nacionalsocialismo tenía de sí: al margen de si hubo o no un abuso, la cuestión es que el uso de Nietzsche en el Tercer Reich no fue meramente ocasional, ni decorativo, sino sistemático ${ }^{17}$. Hasta tal punto que a la propaganda filonietzscheana del Tercer Reich correspondió una

territorios ocupados del este. Huelga decir que ambos fueron juzgados y condenados a muerte en Núremberg.

15. Cf. A. Bäumler, Nietzsche der Philosoph und der Politiker, Leipzig: Reclam, 1931, así como G. Lukács, El asalto a la razón. La trayectoria del irracionalismo desde Schelling hasta Hitler, trad. de W. Roces, Barcelona: Grijalbo, 1967. La primera edición alemana data de 1954, pero las invectivas de Lukács contra Nietzsche se remontan a los años treinta. Cf. W. Jung, «Das Nietzsche-Bild von Georg Lukács. Zur Metakritik einer marxistischen Nietzsche-Deutung»: Nietzsche-Studien 19 (1990), 419-430, así como H. Ottmann, «Anti-Lukács. Eine Kritik der Nietzsche-Kritik von Georg Lukács»: Nietzsche-Studien 13 (1984), 570-586. Precursor de la crítica socialista a Nietzsche lo fue, por lo demás, Franz Mehring: «Nietzsche gegen den Sozialismus» (1897), en Gesammelte Schriften, vol. 13, Berlin: Dietz, 1961, pp. 169 ss.

16. R. Safranski, Nietzsche. Biografía de su pensamiento, trad. de R. Gabás, Barcelona: Tusquets, ${ }^{2} 2002$, p. 359.

17. Cf. S. E. Aschheim, The Nietzsche Legacy in Germany: 1890-1990, Berkeley: University of California Press, 1992, pp. 232 ss., así como la tesis doctoral de H. Langreder, defendida en Kiel en 1971, Die deutsche Auseinandersetzung im Dritten Reich: ein Beitrag zur Wirkungsgeschicht Nietzsches, y R. E. Kuenzli, «The Nazi Appropiation of Nietzsche»: Nietzsche-Studien 12 (1983), 428 ss. 
demonización de Nietzsche, no sólo — como ya hemos indicado- en la Unión Soviética, sino también en Inglaterra y Estados Unidos ${ }^{18}$. No, por cierto, en Francia, donde las primeras interpretaciones políticas de Nietzsche tendieron a impugnar la apropiación nacionalsocialista, como es el caso ejemplar de Bataille, quien publicó en enero de 1937, en un monográfico de la revista Acéphale titulado Réparation à Nietzsche, el texto «Nietzsche y los fascistas», en el que Elisabeth Förster-Nietzsche es «elevada», junto a Richard Öhler ${ }^{19}$, a la categoría de Judas del pensamiento nietzscheano. Los estudiosos de Nietzsche en la Francia de la época tendieron a acercarlo al pensamiento socialista, como por ejemplo Andle ${ }^{20}$ o Lefebvre ${ }^{21}$ en sus respectivas monografías. En general, la intelectualidad de izquierdas francesa, con la notable excepción de Levinas, reivindicó y defendió a Nietzsche frente a los desmanes exegéticos a los que se vio sometido por el nacionalsocialismo, mientras que la derecha más cercana a Maurras y a Action Française - de manera similar a Mussolini, D'Annunzio y el fascismo italiano en general- tendió a interpretarlo pro domo sua, de manera sesgada, asistemática, fragmentaria e interesada.

Si bien la violencia hermenéutica de Bäumler se cifró «únicamente» en su desatención absoluta a una significativa parte del pensamiento nietzscheano y no tanto en su interpretación propiamente dicha del Wille zur Macht, lo cierto es que el resto de los «pensadores» nacionalsocialistas que reivindicaron la obra de Nietzsche, si no contamos a Martin Heidegger entre ellos, apenas sí son dignos de mención. Y, los que lo son, lo son justamente por poner en cuestión la existencia de una identidad sin resto entre Nietzsche y la ideología nacionalsocialista (Heinrich Härtle), por negar toda posible conexión entre ambos (Ernst Krieck) o incluso por denunciar los peligros del nietzscheanismo en relación al Tercer Reich $^{22}$. La nazificación de Nietzsche, que significó a la vez una nietzscheanización del nacionalsocialismo, no fue precisamente producto de la reflexión filosófica, sino de una maquinaria de propaganda que, por medio de estrategias diversas, situó a Nietzsche, o a un cierto Nietzsche en todo caso amputado, en el corazón mismo de la cultura nacionalsocialista oficial.

18. A. Ludovici, «Hitler and Nietzsche»: The English Review 64 (1937), 44-52; M. P. Nicolas, From Nietzsche Down to Hitler [1938], Kennikat, Port Washington, 1970; W. McGovern, From Luther to Hitler, Cambridge, Massachussets: Harvard University Press, 1941. Una interpretación en el ámbito anglófono en la época del Tercer Reich menos tendente a asociar a Nietzsche con el nacionalsocialismo la ofrece C. Brinton en «The National Socialists Use of Nietzsche»: Journal of History of Ideas 2 (1940), 131-150, así como en Nietzsche, Cambridge, Massachussets: Harvard University Press, 1941.

19. De Öhler véase Friedrich Nietzsche und die Deutsche Zukunft, Leipzig: Armanen, 1935.

20. Ch. Andler, Nietzsche, sa vie et sa pensée, Paris: Bossard, 1920.

21. H. Lefebvre, Nietzsche, trad. de A. H. de Gaos, FCE, México, 1972. La edición original francesa data de 1939.

22. Cf. H. Härtle, Nietzsche und der Nationalsozialismus, München: Eher, 1937, así como Ch. Steding, Das Reich und die Krankheit der europäischen Kultur, Hamburg: Hanseatische Verlagsanstalt, 1943. De Krieck son célebres, entre los estudios de la nazificación de Nietzsche, las siguientes ácidas palabras respecto del nacionalsocialismo del autor de Zaratustra: «Fue adversario del socialismo, del nacionalismo y del pensamiento racial. Si prescindimos de estas tres líneas intelectuales, quizá habría podido salir de él un nazi destacado» (citado en S. E. Aschheim, op. cit., p. 253). 


\section{DESPOLITIZACIÓN Y DESNAZIFICACIÓN DEL PENSAMIENTO NIETZSCHEANO}

Con la salvedad de Bäumler, quienes en la Alemania de Hitler consideraron filosóficamente en serio a Nietzsche, contribuyendo así a la postre a su rehabilitación y consiguiente desnazificación, es decir, Karl Jaspers, Karl Löwith y el ya mentado Heidegger principalmente, nunca fueron ideólogos del Movimiento, aun cuando el último pudiese en algún momento pretender hacerlo, invocando justamente a Nietzsche, en su tristemente célebre Rektoratsrede $(1933)^{23}$. En el caso de Heidegger, tan polémico o más que el del propio Nietzsche, nos encontramos con un «filósofo del régimen», mientras que en Jaspers y Löwith lo que encontramos son dos expatriados de la Alemania nazi —uno de ellos judío y el otro «únicamente» esposo de una mujer judía, lo cual le permitió mantenerse en el exilio interior-. Acaso el compromiso mantenido por Heidegger con el NSDAP le llevara a interpretar el pensamiento nietzscheano a partir de La voluntad de poder, pero su lectura, presentada ante sus alumnos entre 1936 y 1940 — es decir, transcurrida la etapa del rectorado — y publicada por primera vez sólo en 1961, es, a diferencia de la de Bäumler, estrictamente metafísica e incluso, en la medida en que pueda decirse que desnazifica a Nietzsche, o que al menos neutraliza políticamente al Nietzsche aclamado por el nacionalsocialismo, puede ser entendida como una suerte de subversión filosófica contra el Tercer Reich ${ }^{24}$.

La interpretación llevada a cabo por Jaspers, profesor de la Universidad de Heidelberg hasta su expulsión de la academia alemana en 1937, precisamente un año después de que su Nietzsche $e^{25}$ viera la luz, participa en este sentido del carácter subversivo que acabamos de conferir a la lectura heideggeriana de la voluntad de poder: se trata de una lectura no oficialista de Nietzsche que, sin embargo, fue elaborada en el seno mismo de las instituciones sometidas, desde 1933, al omnímodo poder del NSDAP. Dicho esto, a nuestro juicio y precisamente con respecto a la cuestión de la relación entre el pensamiento nietzscheano y la filosofía del nacionalsocialismo, resulta más interesante, en cambio, el Nietzsche ${ }^{26}$ de Löwith, publicado en 1935. Discípulo de Heidegger, su contribución a la recepción del autor del Zaratustra en la Alemania de Hitler fue esencial y explícitamente polémica respecto de la interpretación oficial: rescata del olvido, situándola en el centro mismo del «sistema» de Nietzsche, la doctrina del eterno retorno, es decir, precisamente el elemento que el nietzscheanismo oficial del Tercer Reich, incluido el de Bäumler —a quien Löwith elogia no obstante el mérito filosófico de su interpretación-, pretendió extirpar de la obra de Nietzsche.

23. Cf. M. Heidegger, «La autoafirmación de la Universidad alemana», en La autoafirmación de la Universidad alemana, el Rectorado y entrevista del Spiegel, trad. de R. Rodríguez, Madrid: Tecnos, 1989, p. 11.

24. Cf. M. Heidegger, "Conversación de Spiegel con M. Heidegger», en La autoafirmación de la Universidad alemana, cit., p. 64. Como es sabido, la entrevista tuvo lugar en septiembre de 1966, pero no fue publicada sino póstumamente, por expreso deseo de Heidegger.

25. K. Jaspers, Nietzsche. Einführung in das Verständnis seines Philosophierens, Berlin/Leipzig: De Gruyter, 1936.

26. K. Löwith, Nietzsches Philosophie der ewigen Wiederkehr des Gleichen, Berlin: Die Runde, 1935. 
Como ya hemos señalado, las interpretaciones de Nietzsche que llevaron a cabo Heidegger, Jaspers y Löwith durante los funestos años del nacionalsocialismo permitieron ulteriormente, en Alemania y fuera de ella, la rehabilitación del pensamiento nietzscheano. Pero sólo después de la Segunda Guerra Mundial y, por supuesto, sólo en Alemania Occidental. La prohibición de las obras de Nietzsche en el Este perduró hasta la disolución del régimen soviético. En la República Federal, en cambio, el libro de Jaspers, que participó activamente en la desnazificación y reconstrucción de la universidad alemana, fue reeditado ya en 1947 y, por tercera vez, en 1950, mientras que la reedición del trabajo de Löwith hubo de esperar a 1956 y, como ya hemos indicado más arriba, la interpretación de Heidegger no fue publicada hasta 1961, conociendo una reedición parcial, bajo el título Der europäische Nibilismus, en 1967. No se falta a la verdad, entonces, si se afirma que tras la Segunda Guerra Mundial, en aquella parte de la Alemania dividida en la que Nietzsche no era objeto de censura, la investigación sobre el pensamiento nietzscheano se llevaba a cabo bajo el impacto de obras que tuvieron su origen en los años treinta ${ }^{27}$.

Aunque no solamente en Alemania. La propaganda antialemana de la Unión Soviética y de los Estados Unidos, desde finales de los años treinta, afirmaba sin mayores reparos la continuidad entre los planteamientos nietzscheanos y los nacionalsocialistas. Tras la Segunda Guerra Mundial, cuando estas dos grandes potencias se dividieron la tierra, las interpretaciones más detalladas, históricas y académicas surgieron en lucha contra esta nazificación del pensamiento nietzscheano. Los más acérrimos defensores de cada uno de ellos (comunistas soviéticos y conservadores norteamericanos) no dedicaron una especial atención a los matices y ambigüedades que vincularon a Nietzsche con el nacionalsocialismo. Como el nacionalsocialismo alemán fue el enemigo político, el enemigo que forzó la coalición antinatural de soviéticos y norteamericanos, su tradición filosófica y política, junto a su historia, tuvieron que ser condenadas. Tal fue la línea argumentativa. Si bien ideológicamente opuestos, estratégicamente plantearon la misma continuidad entre Nietzsche (y en general gran parte de la tradición filosófica alemana, salvo Marx y la progenie marxista para unos y algunos destellos liberales para los otros) y el nacionalsocialismo. Por eso fue tan importante la interpretación despolitizante de Walter Kaufmann ${ }^{28}$ desde principios de los años cincuenta, de modo que toda consideración medianamente seria de esta cuestión ha tenido que enfrentarse con la obra de este autor, puesto que después de él las interpretaciones asimiladoras de Nietzsche y el nacionalsocialismo no podían seguir siendo sostenidas. Este movimiento reactivo de Kaufmann, que desnazificó y despolitizó el pensamiento de Nietzsche, en respuesta a la primera nazificación y politización del mismo por parte tanto del nacionalsocialismo como de los propagandistas de la Unión Soviética y de Estados Unidos, correspondió con una

27. Cf. P. Köster, «Die Problematik wissenschaftlicher Nietzsche-Interpretation. Kritische Überlegungen zu Wolfgang Müller-Lauters Nietzschebuch»: Nietzsche-Studien 2 (1973), 31-60, así como H. Frey, "Como un ave fénix de las cenizas. El surgimiento de una nueva imagen de Nietzsche en Alemania a partir de los años setenta", en G. Martínez y J. Quesada (eds.), ¿Nietzsche ha muerto? Memorias del I Congreso Internacional, México DF: Hombre y Mundo, 2009, pp. 562-563.

28. W. Kaufmann, Nietzsche. Philosopher, Psychologist and Antichrist, Princeton, New Jersey: Princeton University Press, ${ }^{4} 1974$ [1950]. 
fase europea, iniciada en los años sesenta y deudora de los trabajos de Colli y Montinari, que, situada en un punto medio (Nietzsche no es un precursor del nacionalsocialismo, pero tampoco está exento de toda relación, como podría estarlo, por ejemplo, Feuerbach), comenzó a desarrollar la línea de investigación de la que aún somos deudores y en la que vivimos.

Clausurado el Archivo de Weimar y con las dos Alemanias en proceso tanto de desnazificar como de «desnietzscheanizar ${ }^{29}$ su propia cultura, el renacimiento o renovación de la Nietzsche-Forschung en la universidad alemana occidental, tras el hundimiento del Reich, estuvo mediado por la edición crítica de la obra nietzscheana preparada desde comienzos de los años sesenta por Giorgio Colli y Massimo Montinari, quien, gracias a su militancia comunista, pudo tener acceso a todo aquello que la hermana del filósofo había reunido desde la muerte, en vida, de Nietzsche ${ }^{30}$. El trabajo de Colli y Montinari, que en lengua alemana comienza a ver la luz en 1967, permitió la destrucción de la leyenda de La voluntad de poder sobre la que se construyó la interpretación nacionalsocialista de la obra nietzscheana. Pero también el monumento en que se había convertido el Nietzsche de Heidegger. 1971 es un año decisivo en este proceso de progresiva desnazificación definitiva de Nietzsche: aparece una nueva interpretación de la voluntad de poder, no metafísico-heideggeriana, a cargo de Wolfgang MüllerLauter, y tiene lugar la creación de Nietzsche-Studien, entre cuyos fundadores se cuentan Montinari y el propio Müller-Lauter ${ }^{31}$. El primer número de esta revista, sin la cual no se entiende hoy la investigación sobre el autor de El nacimiento de la tragedia, vio la luz en 1972.

A su vez, en el mundo anglófono, después de Kaufmann y en cierto sentido Stern, aparecieron nuevos estudios que matizaron esa compleja relación. En los años ochenta y noventa se publicaron varias monografías ${ }^{32}$ y artículos $^{33}$ sobre

29. Véase, por ejemplo, O. Flake, Nietzsche: Rückblick auf Eine Philosophie, Baden-Baden: Kepler, 1946. Sobre la desideologización de la cultura alemana después de 1945 y el consiguiente antinietzscheanismo de la época, S. E. Aschheim, op. cit., pp. 296 ss.

30. Sumado a esto el hecho, ya aludido, de que Francia tuvo siempre una imagen de Nietzsche distinta a la alemana, puede decirse que, tras la Segunda Guerra Mundial, el «nuevo Nietzsche» fue creado por franceses e italianos y sólo posteriormente introducido en Alemania. Véase H. Frey, art. cit., pp. 568-569, así como, nuevamente, S. E. Aschheim, op. cit., pp. 296 ss. Importante a estos efectos fue el coloquio de Royaumont de 1964.

31. Cf. W. Müller-Lauters, Nietzsche. Seine Philosophie der Gegensätze und die Gegensätze seiner Philosophie, Berlin/New York: de Gruyter, 1971.

32. R. Eden, Political Leadership and Nibilism. A Study of Weber and Nietzsche, Florida: University Press of Florida, 1982; M. Warren, Nietzsche and the Political Thought, Cambridge: MIT Press, 1988; D. W. Conway, Nietzsche and the Political, London/New York: Routlegde, 1997; Íd, Nietzsche's Dangerous Game, Cambridge: Cambridge University Press, 1997; K. Ansel-Pearson, An Introduction to Nietzsche as Political Thinker, Cambridge: Cambridge University Press, 1994; F. Appel, Nietzsche contra Democracy, Ithaca: Cornell University Press, 1991; P. Bergmann, Nietzsche. The «Last Anti-Political German», Bloomington: Indiana University Press, 1987.

33. W. H. Hokel, «Political Uses and Abuses of Nietzsche in Walter Kaufmann's Image of Nietzsche»: Nietzsche-Studien 12 (1983), 429-435; K. R. Fischer, «A Godfather Too: Nazism as a Nietzschean 'Experiment'», en J. Golom y R. S. Wistrich (eds.), Nietzsche, Godfather of Fascism? On the Uses and Abuses of a Philosophy, Princeton/London: Princeton University Press, 2002, pp. 291-300; H. Sluga, «Fichte, Nietzsche and the Nazis», en Heidegger's Crisis: Philosophy and Politics in Nazi Germany, Cambridge: Harvard University Press, 1993, pp. 29-52; R. Stakelberg, «Nietzsche and 
esta cuestión, resultando de especial relevancia a tales efectos el trabajo de Detwiler, Nietzsche and the Politics of Aristocratic Radicalism (1990), que modificó en gran parte la visión de Kaufmann, al que concedió el tremendo mérito de haber desnazificado el pensamiento nietzscheano en plena guerra fría, pero al que reprochó no haber sido capaz de valorar justamente el alcance inequívocamente político de las propuestas nietzscheanas. Detwiler señala que aspectos importantes como su discurso sobre la raza de señores y el superhombre, su elogio de la guerra y la destrucción, su tendencia a destacar el valor positivo de la crueldad, su inmoralismo y su denigración de la compasión y del racionalismo pudieron generar ciertas asociaciones políticas que en última instancia permiten mantener una relativa afinidad intelectual del nacionalsocialismo con Nietzsche, si bien matiza que dicha afinidad no debe hacernos olvidar que se trata de una más de las múltiples existentes y que otros autores como Weber, Simmel, Freud o Jung también se sintieron afines intelectualmente a Nietzsche ${ }^{34}$.

En el ámbito francófono, por otra parte, la interpretación del pensamiento político de Nietzsche y su vinculación con el nacionalsocialismo ha estado desde sus orígenes muy vinculada a la izquierda. Salvo algunas corrientes minoritarias cercanas al fascismo, como Action Française o los seguidores de Maurras, o el grupo Nouvelle Droite, Nietzsche ha tendido a ser interpretado, bien como un socialista o comunista (Andler, Lefebvre, Bataille), bien como un pensador apolítico o antipolítico cercano a posiciones de izquierdas (el nietzscheanismo de izquierdas de los años sesenta y setenta). Aunque es cierto que en la Francia de posguerra la cuestión del carácter nazi del pensamiento de Nietzsche ha estado muy ligada al problema del nacionalsocialismo de Schmitt y Heidegger (interpretaciones que recursivamente ponen en solfa toda la filosofía de estos autores por su vinculación o afinidad con la ideología nacionalsocialista), la lectura más difundida es aquella que intenta aprovechar aquellos elementos propiamente filosóficos de la filosofía de Nietzsche y para la que la cuestión nacionalsocialista es menos relevante, tendiendo a subrayar el carácter apolítico o antipolítico de su pensamiento. Autores filosóficamente reconocidos como Bataille, Camus, Foucault, Deleuze u Onfray ${ }^{35}$ serían un buen ejemplo de este tipo de interpre-

the Nazis: The Völkisch Reaction to Nietzschean Thought»: Research Studies 51 (1983), 36-46; Íd., "The Philosopher of Fascism? Nietzsche Through the Eyes of Ernst Nolte»: Plate Valley Review 22/1 (1994), 38-47; Íd., "Critique as Apologetics: Nolte's Interpretation of Nietzsche», en J. Golom y R. S. Wistrich (eds.), op. cit., pp. 301-320; H. Williams, «Nietzsche and Fascism»: History of European Ideas 11 (1989), 893-899; L. Hunt, «Politics and Anti-Politics: Nietzsche's View of State»: History of Philosophy Quarterly 2/4 (1985), 453-468; A. McIntyre, "Virtuosos of Contempt': An Investigation of Nietzsche's Political Philosophy through Certain Platonic Ideas»: Nietzsche-Studien 21 (1992), 184-210; C. Diethe, «Nietzsche and Nationalism»: History of European Ideas 14/2 (1992), 227-234; G. Lang, "Misinterpretation as the Author's Responsibility (Nietzsche's Fascism, for instance)», en J. Golom y R. S. Wistrich (eds.), op. cit., pp. 47-65; T. B. Strong, «Nietzsche's Political Misappropiations», en B. Magnus y K. M. Higgins (eds.), The Cambridge Companion to Nietzsche, Cambridge: Cambridge University Press, 1996.

34. B. Detwiler, op. cit., pp. 2 ss.

35. A. Camus, El hombre rebelde, trad. de L. Echávarri, Buenos Aires: Losada, 2003; M. Foucault, Nietzsche, la genealogía, la historia, trad. de J. Pérez Vázquez, Valencia: Pre-Textos, 1997; G. Deleuze, Nietzsche y la filosofía, trad. de C. Artal, Barcelona: Anagrama, 2008; M. Onfray, La inocencia del devenir. La vida de Friedrich Nietzsche, trad. de A. Bixio, Barcelona: Gedisa, 2009. Véase, 
tación. Se trata de una apropiación apolítica o antipolítica a la que se oponen una serie de investigadores que denuncian su inocencia, así como la peligrosidad del pensamiento de Nietzsche, Schmitt y Heidegger y de algunos de sus textos. Nos referimos, principalmente, a la crítica marxista ortodoxa y la crítica antifascista, que siguiendo la temprana interpretación de Lukács (aunque matizando más que éste), consideran a Nietzsche un protofascista ${ }^{36}$, inclinándose a vincular inmediatamente el pensamiento nietzscheano con la versión francesa del fascismo representada por Action Française, Maurras y sus seguidores; y a una serie de autores ${ }^{37}$ no marxistas que señalan las concomitancias entre Nietzsche y el nacionalsocialismo, desde una perspectiva más académica y cercana a los desarrollos anglófonos.

En todo caso, la interpretación más corriente en Francia, ya desde el período de entreguerras (Bataille), consiste en una crítica y una oposición radical a la asociación entre Nietzsche y el nacionalsocialismo, así como en una continua apropiación de Nietzsche por parte de autores cercanos al socialismo y al comunismo, en una imposible combinación que da lugar al nietzscheanismo de izquierdas, desde Georges Palante hasta Michel Onfray. La apropiación de Nietzsche se tiende a realizar siempre desde una perspectiva puramente filosófica, centrada en la lucha contra la tradición del cristianismo, y se aprovechan los elementos anticristianos y su pasión crítica ante toda autoridad y toda tradición, dejando habitualmente de lado la cuestión que aquí nos interesa ${ }^{38}$.

Desde los años setenta ${ }^{39}$, el caso español comparte este patrón general despolitizante y desnazificante, mediado especialmente, aunque no sólo, por autores franceses ${ }^{40}$. En el panorama filosófico español de esa época, dividido en-

en general, L. Pinto, Les neveux de Zarathoustra. La réception de Nietzsche en France, Paris: Seuil, 1995.

36. A. Monville, Misère du nietzschéanisme de gauche. De Georges Bataille à Michel Onfray, Bruxelles: Les Éditions Aden, 2007.

37. J.-P. Faye, Le vrai Nietzsche. Guerre à la guerre, Paris: Hermann, 1998; S. Goyard-Fabre, Nietzsche et la question politique, Paris: Sirey, 1977; F. Laruelle, Nietzsche contre Heidegger, Thèses pour une politique nietzscheénne, Paris: Payot, 1997.

38. No ocurre esto en el caso de Jacques Derrida. Su conferencia sobre la enseñanza de Nietzsche, pronunciada en francés en la Universidad de Virginia (1976) y publicada por primera vez en alemán en 1980, contiene en su tercera parte una reflexión sobre la política que se desprende de las consideraciones presentadas por Nietzsche en Sobre el porvenir de nuestras escuelas. En ella, Derrida no duda en renunciar a «disimular [...] lo que [en Nietzsche] haya podido servir de lenguaje a las más siniestras consignas del nacionalsocialismo» (J. Derrida, Otobiografías. La enseñanza de Nietzsche y la política del nombre propio, trad. de H. Pons, Buenos Aires/Madrid: Amorrortu, 2009, p. 61). Denuncia asimismo la ingenuidad con la que en ocasiones se habla de la «falsificación» nacionalsocialista del pensamiento nietzscheano y destaca el hecho de que «la institución de enseñanza, el único esbozo de institución docente que pudo jamás reivindicar la enseñanza de Nietzsche sobre la enseñanza, fue nazi» (ibid., p. 63).

39. Para la recepción anterior, de corte más literario y cultural, el texto de referencia es G. Sobejano, Nietzsche en España, Madrid: Gredos, 1967. Salvando la lectura del falangismo, especialmente de Primo de Rivera, Ramiro Ledesma Ramos y Ernesto Giménez Caballero (véase ibid., pp. 650-660), la cuestión de Nietzsche y el nacionalsocialismo (y la política en general) apenas fue suscitada.

40. Cf. D. Sánchez Meca, «Nietzsche en España», en M. Garrido, N. R. Orringer, L. M. Valdés y M. M. Valdés (eds.), El legado filosófico español e hispanoamericano del siglo Xx, Madrid: Cátedra, 2009, pp. 970-971. 
tre escolásticos con poder académico pero en declive y marxistas y analíticos emergentes, un nuevo grupo, los neonietzscheanos, en el que destacan F. Savater y E. Trías, reivindica la figura de Nietzsche, un Nietzsche desnazificado y, si no claramente despolitizado, al menos depotenciado políticamente hablando, al servicio de la lucha contra las instituciones, la metafísica, la religión, etc ${ }^{41}$. La despolitización caracteriza también a otras interpretaciones de referencia - trabajos académicos- de los años ochenta, dejando de lado la cuestión polémica de la filiación entre el nacionalsocialismo y Nietzsche. Destaquemos tres: el de Juan Luis Vermal ${ }^{42}$, que representa mejor que ningún otro el influjo de la lectura heideggeriana de Nietzsche en el ámbito universitario español, y las monografías de Remedios Ávila Crespo ${ }^{43}$ y Diego Sánchez $\mathrm{Meca}^{44}$, que dialogan con las principales lecturas continentales de Nietzsche. Hay que llegar a los años noventa para encontrar trabajos que, tras la excesiva despolitización del pensamiento nietzscheano tras 1945 (que reproduce por defecto la excesiva politización anterior), rompan, al igual que Detwiler, con esa posición hermenéutica que no otorga un valor relevante al pensamiento político de Nietzsche y, consecuentemente, no considera el problema de la apropiación del pensamiento de Nietzsche por parte de los ideólogos y filósofos nacionalsocialistas. En este sentido destacan fundamentalmente los trabajos de J. Conill, J. E. Esteban Enguita, J. Quesada y L. de Santiago Guervós ${ }^{45}$.

41. Una suerte de manifiesto de este grupo fue el volumen colectivo En favor de Nietzsche, Taurus, Madrid, 1972, resultado de un seminario en la Universidad Autónoma de Madrid. En el libro, además de Trías y Savater, participan Santiago González Noriega, Pablo Fernández-Flórez, Ángel González García, Ramón Barce, Javier Echeverría y Andrés Sánchez Pascual. Un certero análisis sociológico del neonietzscheanismo se encuentra en varios textos de F. Vázquez García: «Un nietzscheanismo de izquierdas en el campo filosófico español (1969-1982)»: Historia social 79 (2014), 147-166; «La recepción de Nietzsche en el campo filosófico del tardofranquismo: el caso de Fernando Savater (1970-1974)»: Estudios Nietzsche 11 (2011), 127-143; «Rituales de interacción y especies de capital en el neonietzscheanismo español (1968-1976)»: Daimon. Revista Internacional de Filosofía 53 (2011), 47-66.

42. J. Luis Vermal, La crítica de la metafísica en Nietzsche, Anthropos: Barcelona, 1987.

43. R. Ávila Crespo, Nietzsche y la redención del azar, Granada: Universidad de Granada, 1986.

44. D. Sánchez Meca, En torno al superhombre. Nietzsche y la crisis de la modernidad, Barcelona: Anthropos, 1987.

45. De J. Conill, véase El poder de la mentira. Nietzsche y la politica de la transvaloración, Madrid: Tecnos, 1997, pp. 158-210. De J. E. Esteban Enguita véase «Las raíces ideológicas del pensamiento político del joven Nietzsche: la Kultur y la Intelligentsia de la burguesía alemana»: Contrastes 3 (1998), 83-103; «El legado de Nietzsche y su pensamiento político», en J. E. Esteban Enguita y J. Quesada (eds.), Política, historia y verdad en la obra de F. Nietzsche, Universidad de Burgos, Madrid: Huerga y Fierro, 2000, pp. 65-80; «El aristocratismo político de Nietzsche», en Nietzsche y la "gran política»: antídotos y venenos del pensamiento nietzscheano, cit., pp. 183-202; El joven Nietzsche. Política y tragedia, Madrid: UAM, 2004 (el origen del libro se remonta a la tesis doctoral del autor, leída en la Universidad Autónoma de Madrid en 1998 y dirigida por J. Quesada); y, por último, su edición y traducción de F. Nietzsche, Fragmentos póstumos sobre política, Madrid: Trotta, 2004. De J. Quesada, pionero en lo que respecta a una consideración relevante del pensamiento político de Nietzsche, veáse Un pensamiento intempestivo. Ontología, estética y política en F. Nietzsche, Barcelona: Anthropos, 1988; El nibilismo activo. Genealogía de la modernidad, México: Universidad de Guadalajara, 1999, pp. 17-108; y, en especial, La belleza y los humillados. Pidiendo un Sísifo ilustrado, Barcelona: Ariel, 2001, pp. 13-64. De L. de Santiago Guervós, véase 


\section{ESTADO ACTUAL DE LA CUESTIÓN Y CONCLUSIÓN}

A la estrategia de relativización de la importancia del Nachlass del ultimísimo Nietzsche propia de la Kritische Gesamtwerke corresponde, desde los años cincuenta y sesenta, la propuesta de despolitización del pensamiento nietzscheano característica, en Europa, de la interpretación del corpus textual propia de Montinari y, procedente de Estados Unidos, de la obra de Kaufmann, ya estudiada en nuestro artículo ${ }^{46}$. Decisiva en lo que a la historia de la desnazificación de Nietzsche se refiere, este último trabajo presentaba una imagen aséptica de la filosofía nietzscheana, sometida a una reducción cultural, que resultó imposible de mantener en el tiempo ${ }^{47}$. Detwiler, como señalamos ya, fue muy crítico en este sentido. En lo que se refiere a la relación del filósofo con el nacionalsocialismo, la imagen que hoy se tiene de Nietzsche es de hecho más próxima a la presentada por Ernst Nolte - dejando a un lado su definición de Nietzsche como el más importante y radical enemigo del marxismo- en su célebre y polémico análisis histórico-filosófico del fascismo, publicado en Alemania en 1963, o incluso a la expuesta por Franz Neumann, desde el exilio en Norteamérica, ya en $1942^{48}$. Se reconoce, como hecho histórico, cierta relación de filiación intelectual del nacionalsocialismo respecto de Nietzsche, al mismo tiempo que se llama la atención sobre algunos de los aspectos del pensamiento nietzscheano que, o bien fueron ocultados por el nietzscheanismo nacionalsocialista, o bien se situaban a un nivel de profundidad distinto, y que en todo caso impiden la absoluta identificación del mencionado pensamiento con la filosofía del nacionalsocialismo: el rechazo tanto del nacionalismo como del antisemitismo ${ }^{49}$, simbolizado en la ruptura de Nietzsche con Wagner y su propia hermana, así como la reivindicación de un tipo humano y de un aristocratismo a ultranza, resueltamente incompatibles con los postulados völkisch. Si se afirma que Nietzsche fue un precursor del nacionalsocialismo, en el sentido de que éste pudo efectivamente tomar algunos elementos que de hecho cabe encontrar, aun en ocasiones de manera ambigua, en la obra de aquél, de ello no se sigue, sin embargo, que el propio Nietzsche fuera un nazi, sino que, en una interpretación generosa, el nacionalsocialismo

Arte y poder. Aproximación a la estética de Nietzsche, Madrid: Trotta, 2004, pp. 265-319. De principios de los años noventa, véase también J. Sauquillo, «Friedrich Nietzsche», en F. Vallespín (ed.), Historia de la teoría política. 5. Rechazo y desconfianza en el proyecto ilustrado, Madrid: Alianza, 1993, pp. 82-131. Por último, hay que destacar que la crítica de corte lukácsiano, retomada recientemente en el ámbito francés por el ya citado A. Monville, tiene su propia versión española en el texto de N. González Valera, Nietzsche contra la democracia. El pensamiento político de Friedrich Nietzsche (1862-1872), Barcelona: Montesinos, 2010.

46. En esta misma línea, véase también H. Lefebvre, Hegel, Marx, Nietzsche (o el reino de las sombras), trad. de M. Armiño, México: Siglo XXI, ${ }^{5} 1982$ (1976). El original francés data de 1975.

47. Cf. J. E. Esteban Enguita, El joven Nietzsche. Política y tragedia, cit., pp. 27 ss., así como W. H. Sokel, «Political Uses and Abuses of Nietzsche in Walter Kaufmann's Image of Nietzsche»: Nietzsche-Studien 12 (1983), 436-442.

48. Cf. E. Nolte, El fascismo en su época, trad. de M. R. Borras, Barcelona: Península, 1967, pp. 501 ss., así como F. Neumann, Behemoth. Pensamiento y acción en el nacionalsocialismo, trad. de V. Herrero y J. Márquez, México: FCE, 1983, pp. 147 ss. De Nolte véase también su libro, publicado en alemán en 1990, Nietzsche y el nietzscheanismo, trad. de T. Rocha Barco, Madrid: Alianza, 1995.

49. Rechazo, hasta 1876, en aras de la Kultur; en aras de una nueva civilización europea desde esa fecha. 
podría llegar a ser considerado, dentro de la cultura posnietzscheana, como una suerte de experimento nietzscheano, del mismo modo que también podrían serlo el existencialismo, la filosofía analítica o la psicología moderna ${ }^{50}$.

Desde el último cuarto del siglo pasado se concibe en Alemania que una lectura de Nietzsche como Wegbereiter del nacionalsocialismo no es necesariamente propia de académicos particularmente perversos o corruptos siempre y cuando, como en el caso de Henning Ottmann, se especifique que Nietzsche necesitó ser nazificado mediante un ejercicio de popularización, vulgarización, simplificación y manipulación de su pensamiento ${ }^{51}$. El Nietzsche nacionalsocialista fue una caricatura, pero una caricatura fundada en los propios textos de Nietzsche -interesadamente interpretados, debidamente mutilados y, en ocasiones, «corregidos» a discreción-. Una caricatura es, igualmente, un Nietzsche socialista, un Nietzsche anticapitalista o un Nietzsche antipolítico en el sentido que tiene esta expresión en Kaufmann. Nietzsche fue, en definitiva, uno de esos (buenos) alemanes (y europeos) que permanecieron seducidos por el aristocratismo propio de una tradición cultural de Alemania que protestaba contra el mundo de las ideas y valores de la Europa occidental, contra toda revolución que no fuese conservadora de la idiosincrasia cultural alemana y ajena al poder de las masas. Del salto de una Weltanschaunng tal a la «revolución» legal consumada por el nacionalsocialismo no pudo nunca ser responsable intelectual, como tal, Friedrich Nietzsche, sino quienes, a costa suya, quisieron encontrar en su pensamiento la justificación de la más terrible catástrofe vivida nunca por la humanidad. Quienes perversamente le situaron ante sí mismos, en definitiva, tal como el pensamiento antecede a la acción.

50. Cf. K. R. Fischer, «Nazism as a Nietzschean 'experiment'»: Nietzsche-Studien 6 (1977), 116 ss.

51. Cf. H. Ottmann, Philosophie und Politik bei Nietzsche, Berlin/New York: De Gruyter, 1987. Sobre las diferencias concretas entre Nietzsche y Hitler, cf. E. Tugendhat, «Poder y antiigualitarismo en Nietzsche y Hitler» (trad. de V. Durán y G. Meléndez), en G. Meléndez (ed.), Nietzsche en perspectiva, Bogotá: Siglo del Hombre, 2001, pp. 255-294. 